\section{Glandular Odontogenic Cyst}

Sir,

Glandular odontogenic cyst (GOC) is an extremely rare developmental odontogenic cyst of the jawbones exhibiting an aggressive behaviour. ${ }^{1}$

The prevalence of the lesion ranges from $0.012 \%$ to $1.3 \%$ and accounts for $0.17 \%$ of all jaw cysts on average. 2 Although it is clinically seen as a slowly growing asymptomatic swelling, there are cases leading to symptoms. ${ }^{3}$ Radiographically, it is seen in the form of unilocular or multilocular, well-defined, radiolucent lesion frequently crossing the midline. ${ }^{4}$ Its histological characteristic is that the squamous epithelium, lining the cyst, shows duct-like small spaces partly surrounded by mucinproducing cells. The treatment varies from simple surgical enucleation to aggressive resection. The recurrence rate is high. ${ }^{3}$

A 41-year male was referred to the Department of Oral and Maxillofacial Surgery by the dentist who noticed a well-defined radiolucent lesion in the right posterior mandibular region. The patient was healthy and visited the dentist for dental prosthesis. He did not report any dental symptoms. Extraoral examination did not reveal any lesion-related findings such as swelling. Intraorally, non-fluctuant and firm swelling was seen with normal overlying mucosa in the posterior mandible. Panoramic radiographic examination revealed a well-defined unilocular radiolucency in the posterior mandible (Figure 1). The provisional diagnosis was residual radicular or dentigerous cyst, unicystic ameloblastoma, and odontogenic keratocyst. Informed consent was obtained and the lesion was carefully enucleated under local anaesthesia. Histopathological examination revealed mucinous glandular differentiation in the superficial layer of epithelium (Figure 2). A final diagnosis of glandular odontogenic cyst was made. Two months after the surgical procedure, panoramic radiograph showed bone healing (Figure 3).

Glandular odontogenic cyst is a lesion with aggressive behaviour showing a high recurrence rate. Although it is usually seen in the mandibular anterior region, cases are reported with maxillary localisation.

The radiographic appearance of the lesion is usually in the form of oval-shaped, well-defined, radiolucent lesion. However, it may demonstrate an appearance of irregular contours. Radiographically, it may be visualised as a radicular cyst, odontogenic keratocyst, ameloblastoma and lateral periodontal cyst.

Kaplan et al. have devised major and minor criteria for the diagnosis of glandular odontogenic cysts. ${ }^{5}$ Five major criteria should be present to confirm the diagnosis and the presence of four minor criteria support the diagnosis. Major criteria include: non-keratinised squamous epithelial lining with a flat interface, presence of "spherules"/knobs or whorls or focal luminal proliferation, cuboidal eosinophilic cells or "hob-nail" cells, mucous/goblet cells with intraepithelial mucous pools with or without crypts lined by mucous producing cells, and intraepithelial glandular microcystic or duct-like structures. Minor criteria include: lining epithelium with papillary proliferation, ciliated cells, multicystic or multiluminal architecture, clear or vacuolated cells in the basal or spinous layers.

Recurrence rate of the lesion has been reported to be as high as $25 \%$ to $55 \% .^{6}$ Although it shows frequent recurrence, enucleation and curettage are recommended for the treatment of glandular odontogenic cyst. ${ }^{3}$ There are also aggressive treatment options such as marginal resection. There are studies reporting that the glandular odontogenic cyst has a potential of transforming into mucoepidermoid carcinoma. 7,8

Due to the high recurrence rate and the potential of malignant transformation, the treatment and follow-up should be carried out with extreme caution.

\section{PATIENTS' CONSENT:}

Informed consent is obtained from patient to publish the data concerning this case.

\section{CONFLICT OF INTEREST:}

Authors declared no conflict of interest.

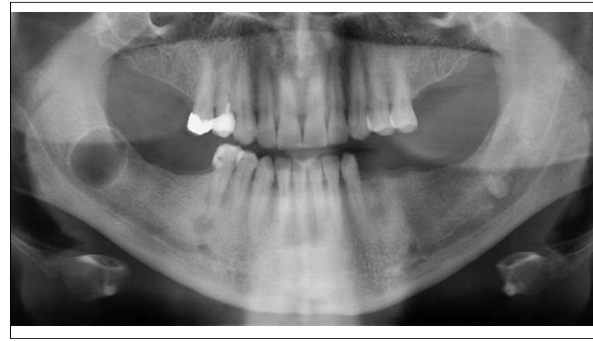

Figure 1: Preoperative panoramic radiograph demonstrating odontogenic cyst in the right ramus of mandible

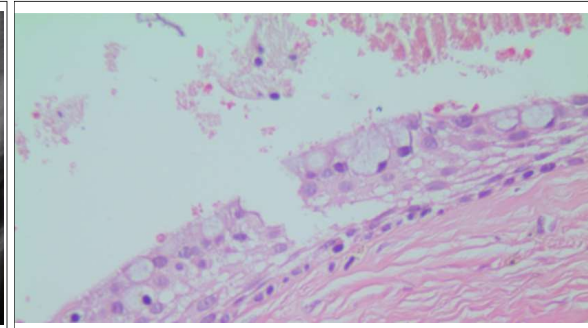

Figure 2: Mucinous glandular cell differentiation in the superficial layer of epithelium. (hematoxylin and eosin staining, magnification $\times 200$ )

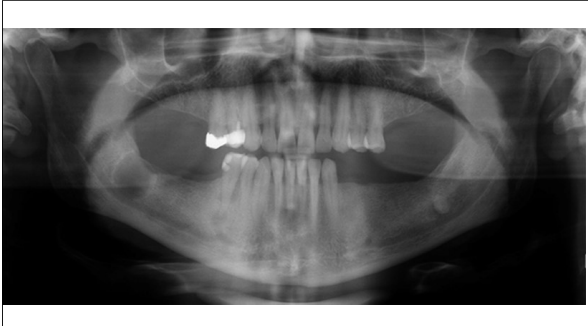

Figure 3: Panoramic radiograph showing good bone healing at 2 months. 


\section{AUTHORS' CONTRIBUTION:}

TU, MB, BCD, EHI, OT: Contributed to the conception of the work; drafted the work; finally approved the version to be published; agreed to be accountable for all aspects of the work in ensuring that questions related to the accuracy or integrity of any part of the work are appropriately investigated and resolved.

\section{REFERENCES}

1. Mascitti M. Glandular odontogenic cyst: Review of literature and report of a new case with cytokeratin-19 expression. Open Dent J 2014; 8:1.

2. Krishnamurthy A. Glandular odontogenic cyst: Report of two cases and review of literature. Head Neck Pathol 2009; 3:2.

3. Freitas Silva BS. 20-year follow-up of recurrent glandular odontogenic cyst mimicking a periapikal lesion. J Endod 2017; 43:11.

4. Faisal M, Ahmad S, Ansari U. Glandular odontogenic cyst Literature review and report of paediatric case. J Oral Biol Craniofac Res 2015; 5:3.

5. Kaplan I, Anavi Y, Hirshberg A. Glandular odontogenic cyst: A challenge in diagnosis and treatment. Oral Dis 2008;14:7.

6. Asthana A, Singh AK. Bilateral glandular odontogenic cyst of the maxilla: A rare case report and review of literature. Int $J$ Med and Dent Sci 2014; 3:2.

7. Economopoulou P, Patrikiou A. Glandular odontogenic cyst of the maxilla: Report of case. J Oral Maxillofac Surg 1995; 53:7.

8. Waldron CA, Koh ML. Central mucoepidermoid carcinoma of the jaws: Report of four cases with analysis of the literature and discussion of the relationship to mucoepidermoid, sialodonto-genic, and glandular odontogenic cysts. J Oral Maxillofac Surg 1990; 48:8.

Tugçenur Uzun ${ }^{1}$, Merve Bozkurt' ${ }^{1}$, Betül Cengiz Duran ${ }^{1}$, Eda Hilal Imamoglu ${ }^{2}$ and Orçun Toptas ${ }^{1}$

1 Department of Oral and Maxillofacial Surgery, Faculty of Dentistry, Abant Izzet Baysal University, Bolu, Turkey

2 Department of Pathology, Faculty of Medicine, Abant Izzet Baysal University, Bolu, Turkey

Correspondence to: Tugçenur Uzun, Department of Oral and Maxillofacial Surgery Faculty of Dentistry, Abant Izzet Baysal University, Bolu, Turkey

E-mail:tugce--nur@hotmail.com

Received: December 20, 2018; Revised: April 09, 2019 Accepted: April 10, 2019 